\title{
Genetic diversity in centipedegrass [Eremochloa ophiuroides (Munro) Hack.]
}

\author{
Jianjian Li ${ }^{1,2}$, Hailin Guo ${ }^{1,2}$, Junqin Zong ${ }^{1,2}$, Jingbo Chen ${ }^{1,2}$, Dandan Li ${ }^{1,2}$ and Jianxiu Liu ${ }^{1,2}$
}

\begin{abstract}
Genetic diversity is the heritable variation within and among populations, and in the context of this paper describes the heritable variation among the germplasm resources of centipedegrass. Centipedegrass is an important warmseason perennial $\mathrm{C}_{4}$ grass belonging to the Poaceae family in the subfamily Panicoideae and genus Eremochloa. It is the only species cultivated for turf among the eight species in Eremochloa. The center of origin for this species is southern to central China. Although centipedegrass is an excellent lawn grass and is most widely used in the southeastern United States, China has the largest reserve of centipedegrass germplasm in the world. Presently, the gene bank in China holds $\sim 200$ centipedegrass accessions collected from geographical regions that are diverse in terms of climate and elevation. This collection appears to have broad variability with regard to morphological and physiological characteristics. To efficiently develop new centipedegrass varieties and improve cultivated species by fully utilizing this variability, multiple approaches have been implemented in recent years to detect the extent of variation and to unravel the patterns of genetic diversity among centipedegrass collections. In this review, we briefly summarize research progress in investigating the diversity of centipedegrass using morphological, physiological, cytological, and molecular biological approaches, and present the current status of genomic studies in centipedegrass. Perspectives on future research on genetics and genomics and modern breeding of centipedegrass are also discussed.
\end{abstract}

\section{Introduction}

Centipedegrass [Eremochloa ophiuroides (Munro) Hack.] is a perennial warm-season $\left(\mathrm{C}_{4}\right)$ grass that originated in China ${ }^{1-3}$. It is indigenous to Southeast Asia and is now widespread, with its distribution, including China (in the Yangtze River Basin and its southern area), Southeast Asia, the eastern and southern United States ${ }^{4}$, some parts of South America, the West Indies, and even parts of Africa ${ }^{5}$ and tropical northern and eastern Australia ${ }^{6}$. It has highly developed stolons during growth in the field and can form a dense canopy that provides

\footnotetext{
Correspondence: Jianxiu Liu (turfunit@aliyun.com)

${ }^{1}$ The National Forestry and Grassland Administration Engineering Research Center for Germplasm Innovation and Utilization of Warm-season Turfgrasses, Institute of Botany, Jiangsu Province and Chinese Academy of Sciences, Nanjing Botanical Garden, Mem. Sun Yat-Sen, 210014 Nanjing, Jiangsu, China ${ }^{2}$ The Jiangsu Provincial Engineering and Technology Research Center for Turf Germplasm Improvement and Breeding, Institute of Botany, Jiangsu Province and Chinese Academy of Sciences, Nanjing Botanical Garden, Mem. Sun YatSen, 210014 Nanjing, Jiangsu, China
}

continuous ground cover (Fig. 1). Centipedegrass is well known for its tolerance to aluminum and good adaptation to infertile soils and a wide range of climatic conditions ${ }^{7,8}$. It has great potential for commercial applications as a low-maintenance turfgrass, with advantages over other turfgrasses, such as lower management and fertilization requirements $^{7,9}$. These properties of low maintenance, good adaptation to poor soil and a broad tolerance to biotic and abiotic stresses make centipedegrass a popular turfgrass across the southeastern United States and in the southern Yangtze River region of China ${ }^{10,11}$. The species is predominantly outcrossing and can be propagated vegetatively or by seed. Centipedegrass is widely used as turf for home lawns and recreational fields and for soil conservation in tropical and subtropical areas of the world; $;^{9,12,13}$ it can also be used as a feed supply for grazing livestock ${ }^{7,14}$. In addition, centipedegrass can potentially be used in environmental remediation due to its tolerance to and ability to absorb heavy metals ${ }^{15,16}$. 

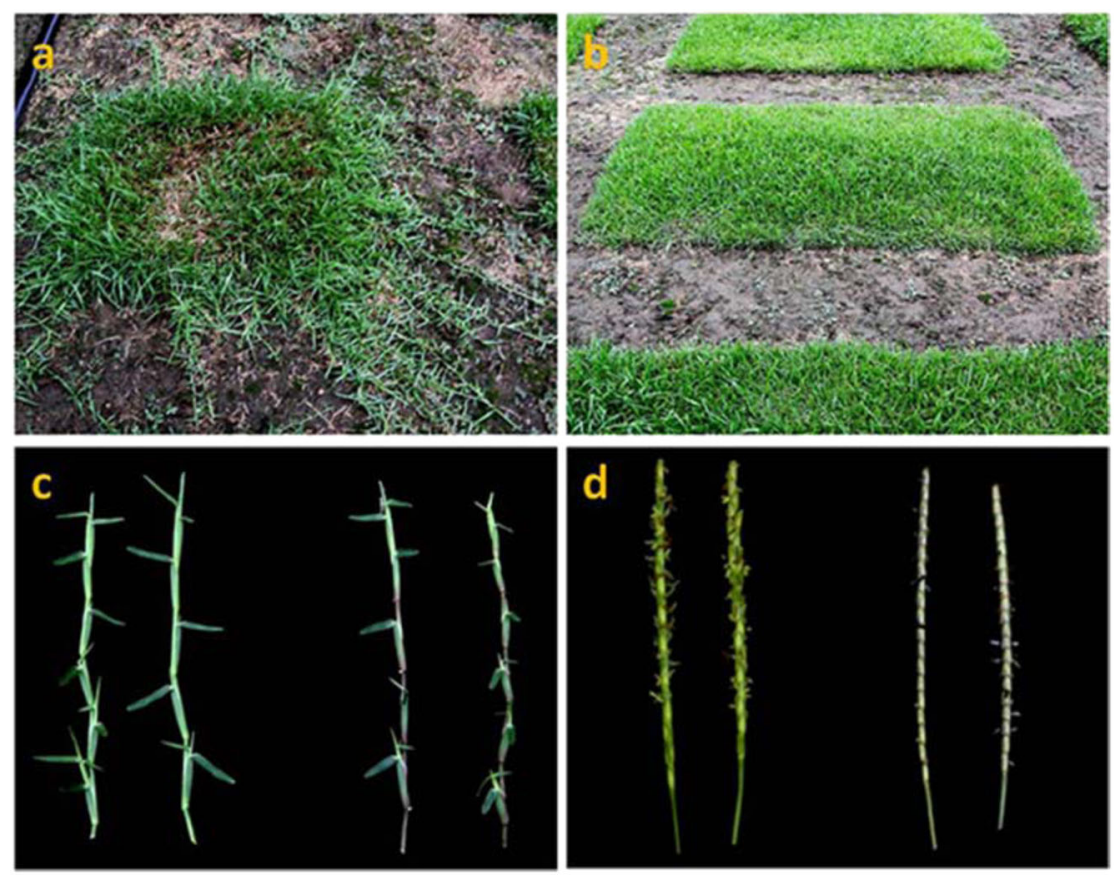

Fig. 1 Photographs of centipedegrass showing a growing plug, a 2 by 1 meter (e.g., $2 \times 1 \mathrm{~m}^{2}$ ) field plot, and two types of stolons and inflorescences. a Stolons growing from a plug in a field. $\mathbf{b}$ Overall appearance of the turf in the field. c Two types of stolons, namely, the green/ yellow type and purple type. $\mathbf{d}$ Two different spikes, namely, a green/yellow spike and purple spike.

Genetic diversity is the key pillar of biodiversity within and between species and within ecosystems. Diversity in plant genetic resources (PGRs) provides an opportunity for plant breeders to develop new and improved cultivars with desirable characteristics ${ }^{17}$. Accordingly, the analysis of genetic diversity and variation in germplasm resources is an important part of turf breeding programs. Centipedegrass is one of the most important turfgrasses in tropical and subtropical regions, and the conservation, characterization, and utilization of its genetic diversity are becoming increasingly important in view of the high demand for high-quality turfgrass and global climatic changes. This demand is primarily because of the need to plant large areas of lawn in newly constructed modern residential areas and sports facilities in rapidly expanding cities in many developing countries.

Here, we present overviews of the results of major studies on the genetic variation in centipedegrass and of the recent progress made in describing centipedegrass diversity, mainly in the United States and China. The information summarized in the present article is of potential value not only for understanding the drivers of genetic variation in centipedegrass, but also for promoting the breeding and improvement of centipedegrass varieties using modern genetic and genomic tools.

\section{Taxonomy and cytogenesis}

Centipedegrass belongs to the genus Eremochloa in the family Poaceae or Gramineae, subfamily Panicoideae, tribe Andropogoneae, and subtribe Rottboelliinae ${ }^{18}$. It is the only species in the Eremochloa genus that is used as turfgrass $^{12}$. Centipedegrass is a $\mathrm{C}_{4}$ plant, similar to maize and sorghum ${ }^{19,20}$.

Centipedegrass is a diploid species with a somatic chromosome number of $2 n=2 x=18^{2,21-24}$ and a genome size of $\sim 800 \mathrm{Mb}^{25}$. Cytological observations of this species revealed that metaphase I of meiosis was mostly regular, with nine bivalents, but 1 to $15 \%$ of the microsporocytes had eight bivalents and two univalents due to a precociously dividing bivalent ${ }^{2}$. Centipedegrass is a sexually reproducing species with high-pollen stainability and normal sexual development involving megasporogenesis and an embryo sac, but it is selfincompatible $^{2,9}$. An artificially induced tetraploid accession of centipedegrass can be generated by colchicine treatment, with an induction rate of $0.2 \%{ }^{26}$. As polyploidization often results in the induction of chromosomal aberrations at the mitotic and/or meiotic level, such ploidy changes through artificial factors contribute to creating new centipedegrass germplasms, which are of high value in terms of sampling for cultivar improvement. However, cytogenetic information for natural accessions, as well as artificial lines of centipedegrass is currently 
limited. In addition, the above-mentioned findings were based on only a portion of centipedegrass samples, and such a small sample size might lead to an underestimation of the genetic diversity in this species. Therefore, it is necessary to use current cytogenetic approaches to carry out ploidy identification and karyotype analysis of more centipedegrass germplasms derived from different provenances or multiple breeding sources.

\section{Conservation of centipedegrass genetic resources}

Practical breeding for high-quality and attractive turf stands relies mainly upon the germplasm resources available to breeders. The major centipedegrass collections are in China and the United States; most of the wild centipedegrass accessions in the United States were originally collected from China and are now maintained in the centipedegrass germplasm collection in Tifton, GA, and the USDA-ARS Plant Genetic Resources and Conservation Unit in Griffin, GA ${ }^{1,7,13,24}$. Currently, the Institute of Botany, Jiangsu Province and Chinese Academy of Sciences, which is one of the most important turf research institutes in China, has the only Engineering Research Center for Germplasm Innovation and Utilization of Warm-season Turfgrasses in the National Forestry and Grassland Administration (NFGA) and has the largest National Main Warmseason Turfgrass Gene Bank (NMWTGB) in China. The NMWTGB preserves centipedegrass genetic resources collected from different geographical regions in China and plant materials imported from the United States. To the best of our knowledge, the NMWTGB maintains the richest centipedegrass resources in the world, with $\sim 192$ accessions, including 11 cultivars initially registered and conserved ex situ (Table S1). Of these accessions, 148 are available for distribution as stolons or seeds. More than one-third of the registered accessions have been evaluated for plant morphological and economic characteristics, as well as phenological features and stress resistance characteristics. In addition, a core germplasm collection of 43 accessions was constructed in the NMWTGB based on heterogeneity and diversity analyses using sequence-related amplified polymorphism (SRAP) markers, which captured $98.74 \%$ of the allelic diversity in the entire collection of 148 accessions ${ }^{27}$. Considering all the deficiencies of a single marker type, the limited number of markers and the inadequate coverage of primitive germplasm resources, a more accurate and updated centipedegrass core collection urgently needs to be reconstructed by using the latest molecular marker techniques and additional collections from its distribution areas, especially those regions that were not visited during previous collection trips.

\section{Phenotypic diversity in centipedegrass}

Centipedegrass is diverse in terms of its morphological and agronomic characteristics. Among all the phenotypic characters, stem node color (yellow and purple, as shown in Fig. 1) and stigma and anther colors show the most obvious variation among natural centipedegrass accessions ${ }^{9,13}$. In general, yellow stem type centipedegrass accessions show white stigmas and yellow anthers, while the purple stem type has stigmas and anthers that are uniformly purple or $\mathrm{red}^{22}$. Although limited morphological variation is present in natural centipedegrass accessions in the United States, the presence of a wide range of genetic variation among the accessions in China has been found, expressed as variability in plant height ${ }^{28,29}$, stolon number and internode length ${ }^{13,30}$, leaf length ${ }^{28,29}$, number of inflorescences and diameter of internodes ${ }^{28,30}$, stem morphology (creeping vs. erect $^{31}$, seed yield ${ }^{32}$, and phenological phases, which mainly include the regreening stage, booting stage, blossom stage, maturity stage, wilting stage, and green period ${ }^{33,34}$. The narrower genetic base of centipedegrass collections in the United States than in China is likely because most of the centipedegrass accessions in the United States originated from a single collection introduced from China'. In addition, variations in some morphological characteristics related to lawn appearance, such as leaf length, plant height, and internode length and diameter, were also detected in centipedegrass hybrid generations ${ }^{35,36}$ (Table 1).

Broadening the genetic base of centipedegrass is an important aspect of its breeding. To achieve this, one option is for many centipedegrass plants from different geographical sources to be randomly hybridized or for crosses between different genetic groups to be made to generate many populations with broad genetic variation. Alternatively, morphological variation in some leaf and stem features can be generated by gamma radiation, as was demonstrated by the development of a series of current cultivars, such as "AU Centennial" "Tifblair"38.

\section{Molecular diversity in centipedegrass}

The introduction of molecular biology techniques has contributed to the progress made in centipedegrass diversity research. In the past, centipedegrass diversity was mainly assessed using phenotypic data, as mentioned above. Recently, much effort has been made to analyze the genetic diversity in centipedegrass by using molecular approaches. The main work included revealing genetic variation in centipedegrass at the protein and DNA levels using protein markers (isozymes) and DNA markers (Table 2), respectively, as well as mining candidate genes responsible for desirable traits from RNAseq data. 
Table 1 Studies on phenotypic diversity in centipedegrass.

\begin{tabular}{|c|c|c|c|c|}
\hline \multicolumn{2}{|c|}{ Germplasm or genotype } & \multirow[t]{2}{*}{ Sites $^{a}$ (no) } & \multirow[t]{2}{*}{ Main variation in } & \multirow[t]{2}{*}{ References } \\
\hline Type & Number & & & \\
\hline Natural accession & 12 & / & Stem and inflorescence color & Bouton et al. ${ }^{22}$ \\
\hline Natural accession & 31 & / & Limited morphological variation & Hanna $^{9}$ \\
\hline Natural accession & 15 & 7 & Inflorescence density, plant height, leaf length & Bai et al. ${ }^{28}$ \\
\hline Natural accession & 31 & 8 & Stolon number and internode length & Liu et al. ${ }^{13}$ \\
\hline Natural accession & 58 & 8 & Fruit characters & Liu et al. ${ }^{32}$ \\
\hline Natural accession & 59 & 8 & Turf height, leaf length & Liu et al. ${ }^{29}$ \\
\hline Natural accession & 36 & 5 & Internode length and diameter & Liu and $\operatorname{Liu}^{30}$ \\
\hline Natural accession & 40 & 5 & Seed yield & Liu and $\mathrm{Liu}^{32}$ \\
\hline Natural accession & 37 & 6 & Phenological phases & Zong et al. $^{34}$ \\
\hline Natural accession & 60 & 13 & Creeping and erect stem morphologies & Zhao $^{31}$ \\
\hline Hybrids $^{b}$ & 89 & / & Leaf length, internode length, turf height and internode diameter & Zheng et $a^{3 .} .356$ \\
\hline
\end{tabular}

${ }^{a}$ The sites represent different administrative and geographical divisions in China

${ }^{\mathrm{b}}$ The hybrids were derived from a cross between a Chinese parent and a USA parent

\section{Protein markers}

Isozymes were among the most widely used markers for genetic variation analysis within and between populations before DNA markers were applied. Although they have now been largely superseded by more informative DNAbased markers, they were an excellent choice for projects that sought only to identify low levels of genetic variation. Early studies on isozymes showed different isoenzyme patterns of esterase and peroxidase among 12 U.S. centipedegrass accessions ${ }^{22}$. For centipedegrass collections or populations in China, several studies were also carried out on the variation in isozymes. Ren et al. ${ }^{39}$ tested peroxidase isozymes and esterase isozymes in five native centipedegrass samples from different areas of Sichuan and found that all five samples showed variations in the two enzymes. Bai et al. ${ }^{40}$ clustered 15 centipedegrass accessions collected from six geographical regions in China into two categories and four groups based on peroxidase isozyme analysis. By comparing peroxidase isozymes, esterase, and malate dehydrogenase isozymes among six populations of centipedegrass derived from geographical regions of mainland China, Xuan, and $\mathrm{Liu}^{41}$ evaluated the genetic diversity in centipedegrass populations and drew the conclusion that the genetic diversity of centipedegrass in China was more abundant within populations than among populations. Liu and $\mathrm{Liu}^{42}$ also revealed abundant genetic diversity in 16 centipedegrass accessions sampled from East China by electrophoretic analysis of peroxidase and esterase isozymes. However, the genetic diversity in centipedegrass revealed by these isozyme markers still needs to be further verified by more accurate DNA markers. In fact, portions of these research findings have already been validated or corrected in subsequent studies using DNA markers.

\section{Molecular markers}

Molecular markers are short sections of DNA that differ among genotypes, and they are widely used for the identification of germplasm, assessment of genetic variation within and among populations, and determination of genetic relationships between various populations. The genetic relationships among five centipedegrass accessions (or cultivars) in the United States were assessed based on DNA amplification fingerprinting (DAF), and the relatively low levels of polymorphism among them suggested that these accessions are closely related and may share a common origin ${ }^{43}$. Similarly, genetic variations among accessions and populations of centipedegrass that were collected from different geographical regions in China were also analyzed in subsequent studies using AFLP $^{44}$, RAPD $^{45}, \operatorname{ISSR}^{46}$, SRAP $^{11,47,48}$, and SSR markers $^{24,49}$. The Nei's genetic distances between nine centipedegrass collections derived from different geographic regions in China ranged from 0.135 to 0.994 for AFLP markers ${ }^{44}$, indicating broad genetic variation among these accessions. Significant variation was also detected in six centipedegrass populations consisting of 50 accessions by RAPD analysis ${ }^{45}$ and among 60 centipedegrass collections from 13 different geographical regions by ISSR analysis ${ }^{46}$, with a much higher level of genetic variation within populations than among populations. However, it is worth mentioning that a higher level of diversity in U.S. cultivars than in Chinese collections was revealed using SRAP and SSR markers; meanwhile, a lack of overlap in the ranges of 
Table 2 Studies on molecular (genotypic) diversity in centipedegrass.

\begin{tabular}{|c|c|c|c|c|}
\hline \multicolumn{3}{|c|}{ Germplasm or genotype } & \multirow[t]{2}{*}{ Technique } & \multirow[t]{2}{*}{ References } \\
\hline Type & Number & From & & \\
\hline Natural accession & 12 & USA & Protein markers & Bouton et al. ${ }^{22}$ \\
\hline Natural accession & 5 & USA & DAF & Weaver et al. ${ }^{43}$ \\
\hline Natural accession & 5 & China & Protein markers & Ren et al. ${ }^{39}$ \\
\hline Natural accession & 15 & China & Protein markers & Bai et al. ${ }^{40}$ \\
\hline Natural accession & 9 & China & AFLPS & Bai et al. ${ }^{44}$ \\
\hline Natural population & 6 & China & Protein markers & Xuan and $\mathrm{Liu}^{41}$ \\
\hline Natural accession & 16 & China & Protein markers & Liu and $\mathrm{Liu}^{42}$ \\
\hline Natural population & 6 & China & RAPD & Xuan et al. ${ }^{45}$ \\
\hline Natural accession & 4 & China & SRAPS & Zheng et al. ${ }^{47}$ \\
\hline Natural accession & 60 & China & ISSRS & Zhao et al. ${ }^{46}$ \\
\hline Natural accession & 57 & China, USA & SRAPS & Milla-Lewis et al. ${ }^{10}$ \\
\hline Natural accession & 55 & China, USA & SSRS & Harris-Shultz et al. ${ }^{24}$ \\
\hline$F_{1}$ hybrids & 89 & China & SRAPS, EST-SSRS & Zheng et al. ${ }^{50}$ \\
\hline$F_{1}$ hybrids & 87 & China & SRAPS, EST-SSRS & Wang et al..$^{51}$ \\
\hline Natural accession & 8 & China & SRAPS & Guo et al. ${ }^{48}$ \\
\hline Natural accession & 14 & China, USA & EST-SSRS & Wang et al. ${ }^{52}$ \\
\hline Natural accession & 43 & China, USA & SSRS & Li et al. ${ }^{49}$ \\
\hline
\end{tabular}

DAF DNA amplification fingerprinting, AFLP amplified fragment length polymorphism, RAPD random amplified polymorphic DNA, SRAP sequence-related amplified polymorphism, ISSR inter simple sequence repeat, SSR simple sequence repeat, EST expressed sequence tag

diversity between the U.S. and most Chinese groups were found, and genetic diversity did not differ quantitatively between the U.S. and Chinese materials but did differ qualitatively ${ }^{11}$. Recently, $\mathrm{Li}$ et al. ${ }^{49}$ developed a large number of SSR markers based on the next-generation sequencing (NGS) approach and detected considerable genetic diversity among centipedegrass accessions by systematically analyzing the genetic variation among accessions in one core collection of 43 centipedegrass accessions. All the accessions were clustered into six groups according to genetic variation, while the genetic relationship among the 43 accessions did not correspond exactly to their geographical locations, which suggested that centipedegrass experienced outward expansion from its origin site, leading to a complex genetic background and evolutionary history. These analyses depicted a high level of polymorphism within cultivars and a dramatic difference in diversity between/among centipedegrass populations.

Owing to the high level of heterozygosity of centipedegrass plants, research progress on genetic map construction and quantitative trait locus (QTL) mapping of major economic traits in centipedegrass has been slow. The first genetic linkage maps of centipedegrass were constructed using SRAP and SSR markers and were based on $89 F_{1}$ progenies of a cross between two centipedegrass ecotypes (E102 and E092-1). The maps consisted of a female linkage map with 89 loci (85 SRAPs and 4 ESTSSRs) and a male linkage map with 71 assigned SRAP $\operatorname{loci}^{50}$. The same research group subsequently produced another set of genetic maps using the same molecular markers from a population of $87 \mathrm{~F}_{1}$ plants derived from crossing two different ecotypes (E142 and E022) and detected a total of 14 QTLs on the nine linkage groups of the maps; the QTLs were associated with seed yield, vegetative traits and cold tolerance, and could explain $8.71-23.61 \%$ of the phenotypic variation ${ }^{51}$. With the rapid development of high-throughput sequencing technology, additional specific molecular markers for centipedegrass can be rapidly developed at low cost. Therefore, constructing high-density genetic maps in centipedegrass will be an important goal for future research and has the potential to identify the genes responsible for traits of interest.

\section{Transcriptomics and genomics}

To date, the transcriptomes from one cultivar and two accessions of centipedegrass have been sequenced ${ }^{49,52}$. 
For the cold-tolerant variety "TifBlair", a normalized transcriptome library was prepared and sequenced from leaves of seedlings, resulting in a transcriptome with 45,575 unigenes and 84,781 contigs ${ }^{52}$. A second normalized library was constructed from various centipedegrass tissues, including leaf, stolon, and spike tissues, resulting in more gene clusters ${ }^{49}$. Furthermore, a comparative RNA-seq study revealed 329 putative gene products differentially expressed between red-purple and green stolons and 829 differentially expressed genes between redpurple and yellow-green spikes ${ }^{49}$. Owing to various environmental adversities during lawn growth, future research endeavors should be devoted to the transcriptomic analysis of centipedegrass in response to cold and drought stresses and of its tolerance to barren and acidic soils, among other environmental stressors.

With the rapid development and wide applications of NGS technologies, genomic research on several grass species has recently moved from small-scale analysis of genetic polymorphisms toward whole-genome sequencing and genome-wide polymorphism surveys. The availability of genomic sequences for a turfgrass species will greatly increase the number of genome-scale investigations of fundamental mechanisms of resistance to biotic and abiotic stresses. However, to date, there have been no reports on centipedegrass whole-genome sequencing or related genome-sequencing projects, while a few such studies have been performed in zoysia ${ }^{53}$ and perennial ryegrass ${ }^{54}$ via NGS techniques.

\section{Centipedegrass diversity in certain stress-related traits}

\section{Drought tolerance}

Drought stress often occurs during the process of lawn growth and management, and it results in a decline in the quality and productivity of turfgrasses. Studies investigating the effect of moisture deficits on the performance of centipedegrass plants ranged from studies of variability in key morphological characters and responses ${ }^{55-60}$ to studies of physiological traits related to turf quality ${ }^{61-66}$. However, systematic studies on genetic variability in drought tolerance among centipedegrass genotypes have rarely been performed, which severely restricts the breeding of drought-tolerant centipedegrass varieties. Nevertheless, there have been a few successful attempts to produce drought-resistant mutants by radiationinduced mutation in centipedegrass seeds ${ }^{67-69}$ and by culture-induced variation in somatic embryogenesis ${ }^{70}$. These mutant plants showed greater tolerance to drought stress and thus could be potential germplasm resources for breeding drought-tolerant centipedegrass. Hence, it will be important to understand genetic variability in drought tolerance within the centipedegrass gene pool in the future.

\section{Salinity tolerance}

Salinity is a detrimental abiotic stressor for turfgrass plant growth in salt-affected soils. Some artificially bred cultivars of centipedegrass show intraspecific variations in morphological characteristics and turf quality related to salinity tolerance; for example, there is a difference in salt tolerance between "TifBlair" (a salt-tolerant cultivar) and "Common" (a salt-sensitive cultivar). Studies on physiological responses to salt stress have revealed significant differences between salt-tolerant and salt-sensitive cultivars/accessions ${ }^{71,72}$. Generally, however, centipedegrass is a salinity-sensitive species, in contrast to other warmseason turfgrasses ${ }^{19,73-77}$.

\section{Aluminum and acidity tolerances}

Aluminum (Al) toxicity is a major limiting factor for plants growing in acidic soils. Wild centipedegrass is mainly distributed in acidic soils in tropical and subtropical regions, so investigating and documenting the effect of such soil conditions on centipedegrass production and productivity is worthwhile. It has been widely assumed that centipedegrass is well adapted to acidic soils and has excellent $\mathrm{Al}$ resistance. A high degree of genetic variation in $\mathrm{Al}$ tolerance in centipedegrass collections in China, as well as in the cultivars "TifBlair" and "Common", was found based on plant growth and physiological responses to $\mathrm{Al}^{78-80}$. A preliminary genetic analysis of aluminum tolerance revealed that aluminum tolerance in centipedegrass is not controlled by a single major gene ${ }^{81}$. Root exudation of citric acid is one of the key mechanisms for $\mathrm{Al}$ tolerance in centipedegrass ${ }^{82}$.

\section{Cold tolerance}

Centipedegrass is sensitive to low temperatures, is vulnerable to freezing injury, and has a poor overwintering ability. Thus, its adaptation is limited to areas with mild winter temperatures. An early study revealed no measurable differences in cold resistance among centipedegrass plants from different sources in the United States ${ }^{83}$. In contrast, several centipedegrass accessions in China showed great differences in cold tolerance ${ }^{84,85}$. The freezing tolerance of centipedegrass was positively correlated with the levels of polyamines (Pas) and antioxidants, the levels of proline and soluble carbohydrates, and the ratio of soluble carbohydrates to $\operatorname{starch}^{86-89}$. The inheritance of cold tolerance in centipedegrass is additive and dominant with epistatic effects and is controlled by two major genes ${ }^{90}$. To date, one QTL for cold tolerance has been identified by constructing a group of genetic linkage maps of centipedegrass ${ }^{91}$. Recently, several centipedegrass mutants have been produced by radiation ${ }^{69,86}$ and by somaclonal variation ${ }^{91,92}$, and the resultant mutants show good cold resistance. These mutants are valuable materials for both centipedegrass research and centipedegrass breeding purposes. 


\section{Conclusions and future perspectives}

The value of germplasm resources is determined by their genetic diversity, availability, and utility. The wide spectrum of genetic diversity in growth phenotypes and stress-related traits in centipedegrass implies great opportunities for genetic improvement through either direct selection or hybridization between parental lines with desirable traits. Cytological and molecular methods have provided powerful tools for a deeper analysis of genetic variation in centipedegrass. Some mutagenized materials have been developed to supplement the natural diversity present in centipedegrass. As in the many studies that were reviewed here, many efforts have been made over the past few decades to estimate and utilize the genetic variation in centipedegrass populations grown in the United States. Nevertheless, due to the limited populations and genotypes of U.S. accessions, the actual diversity is not reflected in the available centipedegrass germplasm. Although wild resources of centipedegrass are abundant in China and have many unique and useful characteristics, such as a diversity of turf performance and levels of stress tolerance, the exploitation and utilization of resources based on their genetic diversity are still limited. Therefore, it is necessary and valuable to further explore the diversity of centipedegrass germplasms that are currently growing in China and other places in South Asia. Such further germplasm exploration and evaluation may lead to the identification of additional improved centipedegrass materials, which could be conducive to the expanded production of high-value turf. Molecular cytogenetic and new sequence-based approaches will provide opportunities for in-depth studies of the genetic variation and phylogenetic relationships among global collections of this species. In view of the above facts, future research should emphasize four aspects: (1) further collection of centipedegrass germplasm from all of its distribution areas, and especially from regions not sampled during previous collection trips, in order to construct a richer and more complete germplasm bank and an updated core collection; (2) cytogenetic studies on the chromosome structure and function of centipedegrass both for breeders and for other scientists interested in the analysis and manipulation of breeding material at the chromosomal level; (3) studies of genomics, transcriptomics, proteomics, and metabolomics in centipedegrass using high-throughput sequencing techniques; and (4) mining and functional research on the genes responsible for desirable traits such as strong aluminum tolerance and good tolerance to infertile soils, which will ultimately aid in cultivar improvement. With this article, the authors hope that the concerted efforts of all stakeholders in research, development, and funding can be united globally to promote the healthy development of the turf industry.

\begin{abstract}
Acknowledgements
We gratefully acknowledge the financial support provided by the Open Fund of Jiangsu Provincial Key Laboratory for the Research and Utilization of Plant Resources (grant no. JSPKLB201841) and the Natural Science Foundation of Jiangsu Province (grant no. BK20171327).
\end{abstract}

Conflict of interest

The authors declare that they have no conflict of interest.

Supplementary Information accompanies this paper at (https://doi.org/ 10.1038/s41438-019-0228-1).

Received: 10 July 2019 Revised: 27 October 2019 Accepted: 13 November 2019

Published online: 01 January 2020

\section{References}

1. Hanson, A. A., Juska, F. V. \& Burton, G. W. in Turfgrass Science (eds Hanson, A. A. \& Juska, F. V.) 370-377 (1969).

2. Hanna, W. W. \& Burton, W. G. Cytology, reproductive behavior and fertility characteristics of centipedegrass. Crop Sci. 18, 835-837 (1978).

3. Osmond, D. L. \& Hardy, D. H. Characterization of turf practices in five North Carolina communities. J. Environ. Qual. 33, 565-575 (2004).

4. Hanna, W. W. \& Liu, J. in Turfgrass Biology Genetics and Breeding 287-293 (Wiley, 2003).

5. Duble, R. L. Turfgrasses-Their Management and Use in the Southern Zone. 2nd edn. 1-336 (Texas A \& M University Press, College Station, TX, 1996).

6. Menzel, C., Broomhall, P. \& Gash, M. Fertilising sporting fields and parks in tropical Australia. In Sport in the City. Proceedings of the Parks and Leisure Australia Conference (Parks and Leisure Australia, Melbourne, 15-18 September, 2002).

7. Islam, M. \& Hirata, M. Centipedegrass (Eremochloa ophiuroides (Munro) Hack.): growth behavior and multipurpose usages. Grassl. Sci. 51, 183-190 (2005).

8. Liu, M. et al. Somatic embryogenesis and plant regeneration in centipede grass (Eremochloa ophiuroides [Munro] Hack.). Vitr. Cell. Dev. Biol. -PI 44 100-104 (2008)

9. Hanna, W. W. Centipedegrass-diversity and vulnerability. Crop Sci. 35, 332-334 (1995).

10. Liu, J., Hanna, W., Elsner, E. \& Zhou, J. Germplasm investigation of centipedegrass in the People's Republic of China. Plant Genet. Resour. Newsl. 132, 53-56 (2002).

11. Milla-Lewis, S. R. et al. Use of sequence-related amplified polymorphism (SRAP) markers for comparing levels of genetic diversity in centipedegrass (Eremochloa ophiuroides (Munro) hack.) germplasm. Genet. Resour. Crop Evol. 59, 1517-1526 (2012)

12. Beard, J. B. Turfgrass: science and culture. (Prentice-Hall, Englewood Cliffs, NJ, 1973).

13. Liu, J., Hanna, W. \& Elsner, E. Morphological and seed set characteristics of centipedegrass accessions collected in China. Econ. Bot. 57, 380-388 (2003).

14. Hirata, M., Kunieda, E. \& Tobisa, M. Preference of cattle grazing conterminous monocultures of centipedegrass (Eremochloa ophiuroides) and bahiagrass (Paspalum notatum) with contrasting regrowth durations. Anim. Sci. J. 88, 909-917 (2017).

15. Takada-Oikawa, N., Kawanabe, S., Oshida, T. \& Ukiya, Y. Comparison of the abilities of centipedegrass (Eremochloa ophiuroides, hack.) and zoysiagrass (Zoysia japonica, steud.) to purify liquid animal waste. Grassl. Sci. 54, 1-8 (2008).

16. Li, X. et al. Physiological analyses indicate superoxide dismutase, catalase, and phytochelatins play important roles in $\mathrm{Pb}$ tolerance in Eremochloa ophiuroides. Int. J. Phytorem. 18, 251-260 (2015).

17. Govindaraj, M., Vetriventhan, M. \& Srinivasan, M. Importance of genetic diversity assessment in crop plants and its recent advances: an overview of its analytical perspectives. Genet. Res. Int. 2015, 1-14 (2015).

18. Watson, L. \& Dallwitz, M. J. The Grass Genera of the World. (CAB International, Wallingford, UK, 1992).

19. Marcum, K. \& Murdoch, C. Salinity tolerance mechanisms of six $C_{4}$ turfgrasses. J. Am. Soc. Hortic. Sci. 119, 779-784 (1994).

20. Crouch, J. A. \& Tomaso-Peterson, M. Anthracnose disease of centipedegrass turf caused by colletotrichum Eremochloae, a new fungal species closely related to colletotrichum sublineola. Mycologia 104, 1085-1096 (2012). 
21. Brown, W. V. A cytological study of some texas gramineae. Bull. Torre. Bot. Club 77, 63-76 (1950).

22. Bouton, J. H., Dudeck, A. E., Smith, R. L. \& Green, R. L. Plant breeding characteristics relating to improvement of centipedegrass. Soil Crop Sci. Fla. Proc 42, 53-58 (1983).

23. Liu, X., Liu, J. \& Guo, H. Preliminary study on germplasm resource diversity of Eremochloa ophiuroides in East China III. Ploidy level and morphological variation of somatic chromosome. Acta Pratacult. Sin. 12, 90-94 (2003). (in Chinese).

24. Harris-Shultz, K. R. et al. Development of simple sequence repeat markers and the analysis of genetic diversity and ploidy level in a centipedegrass collection. Crop Sci. 52, 383-392 (2012).

25. Qu, R., Luo, H. \& Meier, V. D. in Compendium of Transgenic Crop Plants: Transgenic Plantation Crops, Ornamentals and Turf Grasses (eds Chittaranjan, K. \& Timothy, C. H.) (Blackwell Publishing Ltd, 2008).

26. Schwartz, B., Harris-Shultz, K. R., Contreras, R. \& Hanna, W. Colchicine-induced tetraploidy in centipedegrass. Am. Soc. Agron. Abstract. CD-ROM (2010).

27. Zheng, Y. Detection of Genetic Diversity, Construction of Genetic Linkage Map and Mapping QTL in Centipedegrass (Eremochloa ophiuroides). (Nanjing Agricultural University, Nanjing, China, 2009). Ph.D. thesis.

28. Bai, S. et al. Ecological characteristics and morphological variations of centipedegrass in different populations. J. Beijing Forestry Univ. 24, 97-101 (2002) (in Chinese)

29. Liu, J., Zhu, X., Guo, A. \& Guo, H. Morphological variations of Eremochloa ophiuroides and its morphological types. Acta Agrestia. Sin. 12, 183-188 (2004) (in Chinese)

30. Liu, X. \& Liu, J. Preliminary study on germplasm resources diversityof Eremochloa ophiuroides (Munro) hack. in east china II. variation and morphological types. J. Anhui Agric. Univ. 31, 15-21 (2004) (in Chinese).

31. Zhao, Q. Study on genetic diversity of Eremochloa ophiuroides germplasm resources in China. (Hainan University, Haikou, China, 2010). MS thesis.

32. Liu, J., Zhu, X., Guo, A., Guo, H. \& Xuan, J. The analysis on the fruit characters of Eremochloa ophiuroides in China. J. Plant Resour. Environ. 12, 21-26 (2003) (in Chinese).

33. Liu, X. \& Liu, J. Preliminary study on germplasm resources diversity of Eremochloa ophiuroides (Munro) hack. in East China I. Variation of phenological phase. Chin. Agric. Sci. Bull. 20, 180-182 (2004) (in Chinese).

34. Zong, J., Guo, A. \& Liu, J. Study on phenological period of germplasm resource of Eremochloa ophiuroides (Munro.) hack. Chin. J. Grassl. 28, 61-67 (2006) (in Chinese).

35. Zheng, Y., Fu, X., Guo, H. \& Liu, J. Genetic analysis of morphological characters of centipedegrass hybrids. Acta Pratacul. Sin. 18, 264-269 (2009) (in Chinese).

36. Zheng, Y. et al. Analysis of heredity and correlation of reproductive traits in centipedegrass (Eremochloa ophiuroides) hybrids. Acta Pratacul. Sin. 20 283-289 (2011) (in Chinese).

37. Pedersen, J. F. \& Dickens, R. Registration of AU Centennial centipedegrass. Crop Sci. 25, 364 (1985)

38. Hanna, W. W., Dobson, J., Duncan, R. R. \& Thompson, D. Registration of 'TifBlair' centipedegrass. Crop Sci. 37, 1017 (1997).

39. Ren, J., Mao, K. \& Wu, Y. Comparison of peroxidase isozymes and esterase isozymes in Sichuan's native centipedegrass. Acta Pratacult. Sin. 10, 33-37 (2001) (in Chinese).

40. Bai, S. et al. The peroxidase isoenzyme analysis for fifteen Eremochloa ophiuroides (Munro) Hack. germplasm resources. J. Sichuan Univ. (Nat. Sci. Ed.). 39, 952-956 (2002) (in Chinese).

41. Xuan, J. \& Liu, J. Study on the heredity diversity of China native centipedegrass population (II): evidence of alleozyme. Acta Agrestia. Sin. 13,43-46 (2005) (in Chinese).

42. Liu, X. \& Liu, J. Preliminary study on germplasm resources diversity of Eremochloa Ophiuroides (Munro) Hack in east China-analysis of isoenzymes. J. Biol. 22, 18-20 (2005) (in Chinese).

43. Weaver, K. R., Callahan, L. M., Caetano-Anollés, G. \& Gresshoff, P. M. DNA amplification fingerprinting and hybridization analysis of centipedegrass. Crop Sci. 35, 881-885 (1995).

44. Bai, S. et al. AFLP fingerprinting analysis of Eremochloa ophiuroides (Munro) hack. germplasm. High. Tech. Lett. 12, 45-49 (2002) (in Chinese).

45. Xuan, J., Gao, H. \& Liu, J. RAPD analysis of a population of Eremochloa ophiuroides in China. Acta Pratacul. Sci. 14, 47-52 (2005) (in Chinese).

46. Zhao, Q., Bai, C. \& Liang, X. An analysis by ISSR of genetic diversity in Eremochloa ophiuroides in China. Chin. J. Trop. Crop. 32, 110-115 (2011) (in (hinese).
47. Zheng, Y., Wang, Z., Guo, H., Xue, D. \& Liu, J. Optimization of SRAP-PCR system on centipedegrass (Eremochloa ophiuroides) using orthogonal design and selection of primers. Acta Pratacul. Sin. 17, 110-117 (2008) (in Chinese).

48. Guo, $\mathrm{H}$. et al. Identification analysis of eight centipedegrass materials by SRAP molecular markers. Acta Agrestia. Sin. 22, 203-207 (2014) (in Chinese).

49. Li, J. et al. High-throughput SSR marker development and its application in a centipedegrass (Eremochloa ophiuroides (Munro) Hack.) genetic diversity analysis. PLOS ONE 13, e0202605 (2018).

50. Zheng, Y., Guo, H., Zang, G. \& Liu, J. Genetic linkage maps of centipedegrass [Eremochloa ophiuroides, (Munro) hack] based on sequence-related amplified polymorphism and expressed sequence tag-simple sequence repeat markers. Sci. Hortic. 156, 86-92 (2013).

51. Wang, P. et al. Genetic mapping and QTL analysis for seed yield, vegetative characters and cold tolerance in centipedegrass (Eremochloa ophiuroides). Sci. Hortic. 176, 97-104 (2014).

52. Wang, P. et al. Characterization and development of EST-SSR markers from a cold-stressed transcriptome of centipedegrass by illumina paired-end sequencing. Plant Mol. Biol. Rep. 35, 215-223 (2017).

53. Tanaka, $H$. et al. Sequencing and comparative analyses of the genomes of zoysiagrasses. DNA Res. 23, 171-180 (2016).

54. Mollison, E. M. B., Barth, S., Milbourne, D., Milne, L. \& Marshall, D. F. De Novo Genome Sequencing and Gene Prediction in Lolium Perenne, Perennial Ryegrass. Breeding in A World of Scarcity. (Springer International Publishing, 2016).

55. Hook, J. E., Hanna, W. W. \& Maw, B. W. Quality and growth response of centipedegrass to extended drought. Agron. J. 84, 606-612 (1992).

56. Hook, J. E. \& Hanna, W. W. Drought resistance in centipedegrass cultivars. HortScience 29, 1528-1531 (1994).

57. Zhou, H. The Growth and Physiological Responses to Drought Stress and Comprehensive Evaluation of Drought Resistance of Stenotaphrum Secundaum and Eremochloa ophiuroides. (Nanjing Agricultural University, Nanjing, China, 2007). MS thesis.

58. Severmutlu, S. et al. Drought resistance of warm-season turfgrasses grown in mediterranean region of turkey. HortTechnology 21, 726-736 (2011).

59. Hirata, M., Mizuno, S. \& Tobisa, M. Ability of centipedegrass (Eremochloa ophiuroides [Munro] hack.) to spread by stolons: effects of soil, fertilizer, shade and edging. Grassl. Sci. 58, 28-36 (2012).

60. Zhang, J., Unruh, J. B. \& Kenworthy, K. Turf performance of bahiagrass, centipedegrass, and St. Augustinegrass cultivars under a linear gradient irrigation system. Hortic. Sci. 50, 491-495 (2015).

61. Carrow, R. N. Drought resistance aspects of turfgrasses in the southeast: evapotranspiration and crop coefficients. Crop Sci. 35, 1685-1690 (1995).

62. Carrow, R. N. Drought resistance aspects of turfgrasses in the southeast: rootshoot responses. Crop Sci. 36, 687-694 (1996).

63. Huang, B., Duncan, R. R. \& Carrow, R. N. Drought-resistance mechanisms of seven warm-season turfgrasses under surface soil drying: I. shoot response. Crop Sci. 37, 1858-1863 (1997).

64. Huang, B., Duncan, R. R. \& Carrow, R. N. Drought-resistance mechanisms of seven warm-season turfgrasses under surface soil drying: II. root aspects. Crop Sci. 37, 1863-1869 (1997).

65. Han, R. Study on Drought Resistance of Wild Centipedegrass. (Sichuan Agricultural University, Ya'an, China, 2003). MS thesis.

66. Zheng, Y., Cai, Q. \& Liu, J. Response of centipedegrass (Eremochloa ophiuroides (Munro.) hack.) accessions to water stress. Acta Agrestia. Sin. 13, 102-105 (2005) (in Chinese).

67. Xing, B. Screening and Identification of Cold and Drought Resistant Mutants in Centipedegrass Induced by Gamma Ray. (South China Agricultural University, Guangzhou, China, 2008). MS thesis.

68. Chen, J. Study on Physiological Mechanism of Cold and Drought Resistance in Centipedegrass New Accessions. (South China Agricultural University, Guangzhou, China, 2009). MS thesis.

69. Fan, Y. Screening and Identification of Centipedegrass Mutants. (South China Agricultural University, Guangzhou, China, 2010). MS thesis.

70. Liu, M., Lu, S. \& Guo, Z. Selection and physiological identification of somaclonal variants for increased drought resistance of centipedegrass. Acta Pratacult. Sin. 21, 126-132 (2012) (in Chinese).

71. Maeda, Y. et al. Physiological characteristics of salt tolerance in centipedegrass (Eremochloa ophiuroides (Munro) hack. cv. Tifblair). Grassl. Sci. 57, 65-71 (2011).

72. Li, J. et al. Growth and physiological responses of two phenotypically distinct accessions of centipedegrass (Eremochloa ophiuroides, (munro) hack.) to salt stress. Plant Physiol. Biochem. 126, 1-10 (2018). 
73. Zhou, X. \& Cao, F. Effects of soil salt stress on the photosynthesis of zoysiagrass and centipedegrass. Acta Agric. Univ. Jiangxi. 27, 408-412 (2005) (in Chinese)

74. Zhou, X. \& Cao, F. Effects of $\mathrm{NaCl}$ stress on three warm-season turfgrasses. Grassl. Turf 4, 66-69 (2005) (in Chinese).

75. Liu, Y., Cheng, F., Wang, Q., Hu, Y. \& Wang, Z. Salinity stress responses and tolerance thresholds in four warm-season turfgrasses. Acta Pratacult. Sin. 18, 192-199 (2009) (in Chinese).

76. Liu, Y., Du, H., Wang, K., Huang, B. \& Wang, Z. Differential photosynthetic responses to salinity stress between two perennial grass species contrasting in salinity tolerance. Hortscience 46, 311-316 (2011).

77. Liu, Y., Du, H., He, X., Huang, B. \& Wang, Z. Identification of differentially expressed salt-responsive proteins in roots of two perennial grass species contrasting in salinity tolerance. J. Plant Physiol. 169, 117-126 (2012).

78. Yan, J., Chen, J., Zhang, T., Liu, J. \& Liu, H. Evaluation of aluminum tolerance and nutrient uptake of 50 centipedegrass accessions and cultivars. HortScience $\mathbf{4 4}$, 857-861 (2009).

79. Chu, $\mathrm{X}$. et al. Variation of $\mathrm{Al}$ tolerance in the germplasm resources of centipedegrass in china. Acta Pratacult. Sin. 21, 99-105 (2012) (in Chinese).

80. Yan, J., Yu, L., Chen, J., Wang, D. \& Liu, J. The growth and physiology response of Al-tolerant and Al-sensitive centipedegrass accessions on aluminum soil. Acta Pratacul. Sin. 19, 39-46 (2010) (in Chinese).

81. Chu, X., Guo, H., Chen, J., Zong, J. \& Liu, J. Genetic analysis of Al-tolerance in centipede grass. Acta Agrestia. Sin. 20, 518-523 (2012) (in Chinese).

82. Yan, J., Chen, J., Yu, L. \& Liu, J. Aluminum tolerance in centipedegrass (Eremochloa ophiuroides [Munro] hack.): excluding Al from root. Sci. Hortic. 143 212-219 (2012).
83. Johnston, W. J. \& Dickens, R. Cold tolerance evaluation of several centipedegrass selections. Agron. J. 69, 100-103 (1977).

84. Xuan, J., Guo, H., Liu, J. \& Chen, S. Initial identification of cold tolerance in the Eremochloa ophiuroides germplasm resource. Acta Pratacul. Sin. 12, 110-114 (2003) (in Chinese).

85. Wang, P. et al. Evaluation and variation analysis of cold tolerance in Eremochloa ophiuroides. Acta Agrestia. Sin. 17, 547-551 (2009) (in Chinese).

86. Chen, J., Guo, Z., Fang, J. \& Lu, S. Physiological responses of a centipedegrass mutant to chilling stress. Agron. J. 105, 1814-1820 (2013).

87. Fry, J. D., Lang, N. S., Clifton, R. \& Maier, F. P. Freezing tolerance and carbohydrate content of low-temperature-acclimated and nonacclimated centipedegrass. Crop Sci. 33, 1051-1055 (1993).

88. Cai, Q., Wang, S., Cui, Z., Sun, J. \& Ishii, Y. Changes in freezing tolerance and its relationship with the contents of carbohydrates and proline in overwintering centipedegrass (Eremochloa ophiuroides (Munro) hack.). Plant Prod. Sci. 7, 421-426 (2004)

89. Wang, D. et al. Relationships of freezing tolerance and the contents of carbohydrates, proline, protein in centipedegrass (Eremochloa ophiuroides (Munro.) hack.). Acta Agrestia. Sin. 18, 816-822 (2010) (in Chinese).

90. Wang, P. et al. Genetic analysis for cold tolerance of F1 hybrids in Eremochloa ophiuroides. Acta Pratacul. Sin. 20, 290-294 (2011) (in Chinese).

91. Yuan, X., Wang, Z., Zheng, Y., Liu, J. \& She, J. Acquisition and identification of cold-resistant somatic mutants of centipedegrass. Acta Pratacul. Sin. 20 237-244 (2011) (in Chinese).

92. Liu, M., Lu, S. \& Guo, Z. Chilling-tolerant variants screening and physiological identification of centipedegrass. Acta Agrestia. Sin. 19,652-656 (2011) (in Chinese). 